\title{
La modalidad posneoliberal de intervención en el agro: el Estado para los agroexportadores y agroindustriales
}

\section{Agriculture intervention under post-neoliberal modality: the State for agro-exporters and agro-industrialists}

\author{
Tito Madrid ${ }^{1 *}$ \\ ${ }^{1}$ Universidad Andina Simón Bolívar.
}

凶 Autor para correspondencia: tivisin@gmail.com

\begin{abstract}
Resumen
El estudio revisa la política agraria del Estado ecuatoriano durante el periodo 1994-2015. Se observa la modalidad posneoliberal de intervención del Estado en el agro. La acción estatal se puede resumir en tres puntos: a) la eliminación de la reforma agraria, por la casi nula repartición de tierras y su reemplazo por el proceso de titularización; b) el fomento de la agroindustria y la agricultura de exportación por medio de una gran cantidad de leyes, decretos y acuerdos ministeriales, así como con la creación de organismos ad hoc para la gestión de las condiciones de mercado para determinados productos; y c) la vinculación de las UPA familiares campesinas e indígenas con la agroindustria, todo bajo la hegemonía de los grandes capitales, con el nombre de negocios inclusivos. De esta manera, las prácticas de Estado en el agro ecuatoriano se muestran parciales hacia la clase capitalista y refractarias a un modelo de economía campesina.
\end{abstract}

Palabras clave: política agraria, reforma agraria, agroindustria, agroexportación, encadenamientos productivos.

\begin{abstract}
The study reviews the agrarian policy in Ecuador during the period from 1994 to 2015. The modality of state intervention in agriculture was observed. The goberment action can be summarized in three points: a) the elimination of the agrarian reform, because the lack of land distribution and its replacement by property registration process; b) the promotion of agro-industry and agriculture for exportation through a large number of laws, decrees and ministerial agreements, as well as the creation of ad hoc bodies for management of market conditions for products; and c) the connection of the Agricultural Production Unit, peasant and indigenous families with the agroindustry, all under the hegemony of the big capitals, under the name of inclusive businesses. In this way, State practices in the Ecuadorian agriculture are partial towards the capitalist class and refractory in a model of peasant economy.
\end{abstract}

Keywords: agrarian policy, agrarian reform, agroindustry, agroexportation, productive linkages.

\section{Introducción}

Este artículo se centra en un momento comprendido entre el cierre de la reforma agraria, simbolizado en la emisión de la Ley de Desarrollo Agrario de 1994, y la expedición de la Ley de Tierras y Territorios Ancestrales en 2015. La investigación centra su atención en la modalidad posneoliberal de intervención del Estado en el agro ecuatoriano y los efectos de la política agraria en las relaciones de poder dentro de esta rama de la economía, con énfasis en la distribución de los medios de producción y los vínculos entre las clases sociales.

El primer apartado brinda una breve descripción de la estructura agraria del Ecuador que permite contextualizar la intervención en la política agraria con énfasis en el periodo 1994-2015. Incluye un estudio 
de la concentración de la tierra y su distribución en diferentes estratos, de acuerdo al tamaño de la Unidad de Producción Agrícola (UPA), el acceso a agua de riego, maquinaria agrícola y crédito y, sobre todo, las condiciones de posibilidad que genera para el desenvolvimiento de las relaciones sociales. El segundo apartado, presenta una revisión sucinta sobre el fin de la reforma agraria, por la casi nula repartición de tierras y su reemplazo por el proceso de titularización, constituyendo al mercado como el principal canal de redistribución de tierras. Posteriormente, presenta una discusión sobre lo que consideramos como "modalidad posneoliberal de intervención del Estado en el agro" y, finalmente, se presentan tres herramientas de intervención del Estado: a) los encadenamientos productivos y la agricultura por contrato; b) las políticas de impulso a las exportaciones y la agroindustria que incluyen: el análisis del presupuesto estatal para la agricultura, la normativa agraria y la política de precios; y c) un balance del poder económico de la agroindustria y la agricultura de exportación.
Para terminar, en las conclusiones, tratamos de dar una caracterización de este modo de intervención del Estado en el sector agropecuario y, desde una perspectiva histórica, comentar las transformaciones ocurridas en el Estado.

\section{Concentración de los medios de producción en el campo}

La política de reforma agraria iniciada en la década de 1960 aceleró el proceso de transformación de la estructura agraria ecuatoriana. Además, del crecimiento de la superficie agrícola, también se modificó la tenencia de la tierra por el crecimiento del número de Unidades de Producción Agrícola (UPA) entre 1954 y el 2000 en $145 \%$, esto es, 496.811 UPA más (Ramón, p. 1991: 159; Rosero et al., 2011, p. 25). Todo esto provocó cambios en los sujetos que están detrás de la tenencia o carencia de este recurso (ver Tabla 1).

Tabla 1. Superficie agrícola (\%), variación del número de UPA (\%) e índice de Gini 1954-2013

\begin{tabular}{|c|c|c|c|c|c|c|}
\hline \multirow{2}{*}{$\begin{array}{c}\text { Tamaño } \\
\text { (has) }\end{array}$} & \multirow{2}{*}{1954} & \multirow{2}{*}{1974} & \multirow{2}{*}{2000} & \multirow{2}{*}{2013} & \multicolumn{2}{|c|}{ Crecimiento número UPA } \\
\hline & & & & & 1954-2000 & 2000-2013 \\
\hline Menos de 1 & 0,7 & 0,9 & 0,8 & 0,7 & \multirow{2}{*}{$111,90 \%$} & $-18,40 \%$ \\
\hline $1-4,99$ & 6 & 6,8 & 5,5 & 5,8 & & $1,80 \%$ \\
\hline $5-19,99$ & 8,8 & 13,4 & 13,8 & 16,8 & $161,20 \%$ & $15,20 \%$ \\
\hline $20-99,99$ & 17,8 & 24 & 37,3 & 43,1 & $301,20 \%$ & $14,70 \%$ \\
\hline 100 y más & 66,6 & 54,8 & 42,6 & 33,5 & $173,30 \%$ & $10,90 \%$ \\
\hline Índice de Gini & 0,87 & 0,85 & 0,85 & 0,76 & & \\
\hline
\end{tabular}

En principio destacaremos dos polos en esta estructura. Primero, se constata un crecimiento importante de los minifundios. El número de UPA menores a 1 ha creció en 35,5\% entre 1954-1974 y su tamaño promedio se redujo de 1,71 a 1,53 ha (Chiriboga 1985, p. 100), generando una capa de campesinos pobres: sin tierras, como arrendatarios u ocupantes ilegales. Segundo, entre 1954-1974 los latifundios decrecieron. Las haciendas superiores a 1.000 ha redujeron un $29 \%$ pasando de 705 a 573 UPAS (Hidalgo 2010, p. 74). Pero estos datos no pueden llevar a confusiones ni conclusiones a priori. El latifundio sobrevivió, también, en el sistema de multipropiedad que implica que un mismo propietario posea varios predios separados. La evidencia sobre esto se remonta en la Sierra al sistema de "multi-hacienda" de la década de 1970 (Ramón 1991, p. 117) y se repite en estudios recientes como en Rodríguez (2008, p. 71) que evidencia un acaparamiento significativo de tierras también en la Costa.

La emergencia de una mediana propiedad la transformó en la forma predominante de la estructura agraria puesto que el crecimiento de las UPA entre 5 y 100 ha son producto de la fragmentación de las UPA mayores de 100 ha que evidencian la ruptura 
del latifundio de viejo tipo (García 2006, p. 74; Hidalgo 2010, p. 71-72). Es claro el crecimiento numérico de las UPA campesinas y el minifundio. Las UPA de entre 0 y 2 ha eran el $40 \%$ del total para el 2000, parecería que su importancia declina para 2013 (SIPAE, 2007, p. 43; MAGAP, 2016, p. 155) y también se reduce ligeramente el territorio bajo su control.

Por otra parte, crece la productividad agrícola mediante el uso de la técnica. La tierra, el riego, la maquinaria agrícola, los insumos, la investigación agropecuaria y el crédito no fueron propiedad del campesinado pobre (Vos 1988, p. 453) ni lo son ahora. Veamos los indicadores.

- $\quad$ El agua de riego es un privilegio de pocos, "el $88 \%$ de los regantes-minifundistas dispone de entre el $6 \%$ y el $20 \%$ de los caudales totales de agua disponibles, mientras que el $1 \%$ a $4 \%$ del número de regantes-hacendados dispone del $50 \%$ a $60 \%$ de dichos caudales" (SENPLADES, 2009, p. 145).

- La maquinaria agrícola es utilizada por los grandes propietarios a nivel nacional y por los campesinos capitalizados, especialmente en la Sierra, y el sector agroindustrial (Carrillo, 2016, p. 10).

- $\quad$ El acceso al crédito fue restringido para los campesinos más pobres y centralizado en las provincias con presencia de la agricultura capitalista moderna, vinculada a los productos de exportación $\mathrm{y}$, especialmente, a la ganadería (MAGAP, 2016, p. 214). Solo el 10,4\% y el 7,4\% de las UPA accedieron a crédito en 1974 y en 2000 respectivamente (Chauveau, 2008, p. 195; Cosse 1984, p. 49).

Se puede observar una importante modificación en el proceso de producción caracterizada por la concentración de los cambios técnicos entre las clases dominantes (terratenientes-capitalistas) y los campesinos capitalizados. Se denota que las condiciones estructurales de la propiedad agraria no se reducen a la posesión sobre la tierra, sino al conjunto de medios de producción necesarios para la realización de la actividad agropecuaria. De esta manera, se configura un nuevo nivel de disputa en el sector agrario. No es más el problema de la tierra a secas, ni siquiera la sola monopolización de las mejores tie- rras, sino que arribamos al problema de los medios de producción del agro en su conjunto.

El acceso a créditos, infraestructura productiva e insumos parece estar estrechamente relacionado con la distribución de la tierra (Vos, 1988, p. 452). El problema es que al cambiar las condiciones de producción se transforma, junto a ellas, el entorno de competitividad en el mercado de productos agropecuarios. En este nuevo contexto, la política de laissez faire, laissez passer -aplicada únicamente al campesinado más pobre- hace que los sectores históricamente relegados del campo compitan en condiciones cada vez más desfavorables en el mercado y terminan por precarizar las condiciones de producción y pauperizar las condiciones de vida de este segmento del campesinado. De esta manera, se incrementó la tendencia a cubrir los ingresos por medios extra parcelarios. "Si hasta 1962 los ingresos obtenidos fuera de la finca fueron de alrededor del $20 \%$ de los ingresos campesinos, este porcentaje aumentó a 52\% hacia 1974" (Martínez, 1984, p. 84) y esto era particularmente grave en las UPA menores de 20 ha (Vos 1988, p. 25).

\section{La "muerte" de la reforma agraria: la titulación de tierras}

Al estudiar la actuación del Estado ecuatoriano en el agro, tenemos presentes las palabras de Marx (en Artous, 2016, p. 274), quien decía que:

Es siempre en la relación inmediata de producción entre los propietarios de los medios de producción y el productor directo [...] donde hay que buscar el secreto más profundo, el fundamento escondido de todo el edificio social y, por consiguiente, de la forma que adopta la relación de soberanía y dependencia, en resumen, la forma específica que reviste el Estado en un periodo dado.

No obstante, Marx también advierte que lo característico del Estado moderno es "la disociación de las relaciones de propiedad y las relaciones de soberanía" (Artous, 2016, p. 256). De allí que no basta un calificativo para dar cuenta de su carácter, siendo necesario comprender las mediaciones entre el Estado y la clase económicamente dominante ${ }^{1}$ porque

1 "Si alguien tergiversa, haciendo del factor económico el único determinante, convierte esta tesis en una frase vacía, abstracta y absurda" (Engels en Neto, 2011, p. 14). 
estas indican que las relaciones de producción no se presentan directamente y permiten, precisamente, articular totalidades ${ }^{2}$ (Neto, 2011, p. 57) como, en nuestro caso, la producción agraria. Consideramos que el campo de la construcción y puesta en ejecución de las políticas agrarias es uno de los espacios que evidencia la presencia de estas mediaciones que se constituyen en "técnicas de gobierno" (Foucault, 1991, p. 18) o, como sostenemos en este artículo, modalidades $^{3}$ de intervención del Estado en la actividad social mediante narrativas y prácticas que refuerzan las relaciones existentes en un momento dado de la historia.

La modalidad posneoliberal de intervención del Estado en el agro se diferencia del neoliberalismo porque en ésta la política de Desarrollo Rural Integral (DRI) es anulada, los Organismos de Desarrollo Regional (ODR) terminan por desaparecer y las Organizaciones No Gubernamentales (ONG) juegan un rol secundario. Por otra parte, el discurso sobre la productividad agrícola es de actualidad ${ }^{4}$, pero las prácticas estatales para su desarrollo están focalizadas en la potenciación tanto de las políticas de impulso a estos grupos como en las actividades de encadenamientos productivos y agricultura por contrato, en el contexto del crecimiento rampante del poder económico del sector agroindustrial y agroexportador (ver Tabla 2).

El tránsito entre la modalidad neoliberal y la posneoliberal se produjo al finalizar la reforma agraria, en 1994, pero el período de predominio de esta forma de intervención se evidencia en el año 2000, con los primeros signos de recuperación tras la crisis económica de 1999.

La Ley de Desarrollo Agrario de 1994 fue caracterizada como "contra reforma agraria" (Carrillo 2013, p. 201) "en razón de orientarse este tipo de "reforma" hacia un objetivo estratégico de conservación del statu quo" (García en Barsky, 1988, p. $15)$, poniendo fin al proceso de reforma agraria. Sin embargo, a diferencia de los sucesos acaecidos con anterioridad, el potente levantamiento de la Confederación de Nacionalidades Indígenas del Ecuador (CONAIE) en 19945, que fue el corolario de un nuevo ciclo de protestas en el campo6, obligó a mo-

2 "Para Marx, la sociedad burguesa es una totalidad concreta. No es un "todo" constituido por "partes" funcionalmente integradas [...sino que está] constituida por totalidades de menor complejidad. Ninguna de esas totalidades es "simple", lo que las distingue es su grado de complejidad, [...] la sociedad burguesa puede ser comprendida como un complejo constituido por complejos. Y hay totalidades más determinantes que otras" (Neto, 2011, p. 55-57).

3 Utilizamos el término "modalidad" porque da cuenta no solo de la construcción de una "política" pública cuanto de la presencia de relaciones de poder y de su articulación con el Estado. De la misma forma evitamos recurrir a la noción de "período", por cuanto el uso de estas "técnicas de gobierno" no aparece taxativamente de un momento a otro, sino que maduran en el seno de otra modalidad de intervención estatal hasta que se hacen predominantes e, incluso en esas condiciones, conviven por un tiempo con otras prácticas estatales en declive. Tampoco apelamos a la idea de "régimen" porque puede confundirse con la noción de "régimen de gobierno" o con gobierno, nociones que se refieren a aspectos distintos de los aquí tratados.

Para mayor abundancia ver Madrid (2018).

5 El levantamiento se produjo en medio de la reanimación de la iniciativa campesina y el resurgimiento de las demandas indígenas en torno al agro. Estaba en marcha una cierta redistribución de la tierra con la asignación, desde 1992, de un fondo de tierras administrado por el FEPP y trocado por deuda externa. Se adjudicaron 385.660 ha, de las cuales el 93\% correspondió a la legalización de la tenencia y el resto a negociación y compra de tierras (COTECA, 2000, p. 119; Barrera, 2001, p. 161-162). De este último grupo de tierras, según Ospina (2011, 46), el "61\% era de calidad "mediana y mala" [...] y solo el $10 \%$ era de buena calidad (solo $6 \%$ con riego)". Entre los predios legalizados pesan las adjudicaciones colectivas, como en el caso de la Sierra centro y en la Amazonía. "De las 978.725 ha legalizadas en 1990, 630.869 fueron en la provincia de Pastaza, de las cuales 612.560 corresponden al territorio Huaorani.// El año de mayor legalizaci6n fue 1992 con 1'505.831 ha de las cuales 1'239.565 ha corresponden solo a la provincia de Pastaza, con un promedio de 9.114 ha/beneficiario" (Gondard \& Mazurek, 2001, p. 23).

A lo largo del periodo las organizaciones campesinas, indígenas y las cooperativas construyen procesos unitarios de presión manteniendo tomas de haciendas a lo largo del periodo 1974-1994 con mayor intensidad desde 1988 -5 tomas de las sedes del IERAC, 5 marchas locales y 3 nacionales, 12 levantamientos indígenas, 4 paros campesinos nacionales e, incluso, la toma del Congreso Nacional 1991- para enfrentar los constantes arrestos y desalojos que no hicieron más que acumular la creciente presión sobre la tierra. Además, las organizaciones campesinas e indígenas tuvieron fuerte incidencia en el periodo 1990-2005, entre los hechos más relevantes está la victoria contra la privatización en el referéndum de 1995 y los múltiples paros y levan- 
dificar la ley, eliminando, v. g., la propuesta de privatización del agua. El texto final de la ley de 1994 reconoce la función social de la tierra agregando la necesidad de conservación de los recursos naturales entendida, por un lado, como incrementar la productividad de la tierra y, por otra parte, como la liberalización del mercado de tierras sobre todo rústicas y comunales. La expropiación solo se contempló al existir presión demográfica, pero bajo un procedimiento tan complejo que se tornó inaplicable7. Por último, un organismo de carácter administrativo, el Instituto Nacional de Desarrollo Agrario (INDA), sustituyó al IERAC.

La normativa posterior no modificó en la práctica la propuesta neoliberal. En 2003 se aprobó el Reglamento de la Ley de Desarrollo Agrario que delimita el trámite de titularización y adjudicación de tierras rústicas. La normativa posterior mantedría el mismo panorama. El "Mandato Agrario" (Mandato 16 de la Asamblea Constituyente) de 2008 entregó subsidios para los insumos (exoneración del IVA, impuesto a la renta, ventas subsidiadas por el Estado) y eliminó la contribución al Fondo de Electrificación Rural y Urbano Marginal (FERUM) que sería competencia del Estado. Estas medidas de acuerdo a
Rosero et al. (2011, p. 93-94) "beneficiaron directamente a industriales del sector de alimentos y no a los pequeños productores".

El mercado se convirtió en el canal principal de la redistribución de tierras desde la década de 1990 incluso en los intercambios informales y mediados por la costumbre entre los campesinos pobres. Así en zonas de alta productividad de la tierra su precio aumentó como, por ejemplo, en Ayora -cantón Cayambe- donde una hectárea estaba valorada en 40.000 dólares (Laforge, 2008, p. 213). Por eso, la Compañía Técnica Agropecuaria -COTECA- (2000, p. 104-105) señaló que la reforma agraria se transformó en política de titulación de tierras, apoyada, en primer lugar, por el BID “que financió el Proyecto de Regularización y Administración de Tierras Rurales (PRAT); y, el segundo mecanismo, respaldado por el Banco Mundial, basado en el canje de la deuda externa para financiar la compra de tierras para los campesinos".

En 2009, la Ley de Soberanía Alimentaria expresa la necesidad de garantizar el acceso a la tierra, no con la redistribución -política que entre 2009 y 2015 entregó menos del $0,3 \%$ del total de

tamientos, que consiguieron incluso la salida de tres presidentes de la República. Las medidas de hecho también crecieron en capacidad de convocatoria. Se pasó de una movilización de 5.000 personas en Samborondón en 1973 a más de 40.000 en Riobamba en 1990. Para 1991-1992 se registran entre 111 y 260 conflictos de tierras, entre 49 y 72 se encontraban en Chimborazo y 29 en Cotopaxi y una importante cantidad en la Costa, y una vorágine de juicios represados en 1990 que totalizaban 899. La influencia de las organizaciones campesinas e indígenas fue tal que, para 2007, se registraban más de 200 Organizaciones de Segundo Grado (OSG), 91\% localizadas en la Sierra. Esto supera 1, 2 millones de indígenas organizados y, de estos, el 76\% se nucleaba en las comunas. Sus organizaciones más representativas eran: la CONAIE -en 16 provincias (con excepción de Carchi y casi todas las provincias de la costa) y alrededor de 804.800 miembros-, la FENOCIN -en 7 provincias y alrededor de 109.000 miembros de base- y la FEINE -en 4 provincias con alrededor de 26.300 miembros-.

7 Las causales de expropiación son "Las tierras rústicas de dominio privado sólo podrán ser expropiadas en los siguientes casos: a) Cuando sean explotadas mediante sistemas precarios de trabajo o formas no contempladas en esta Ley como lícitas; b) Cuando para su explotación se empleen prácticas, incluyendo uso de tecnologías no aptas, que atenten gravemente contra la conservación de los recursos naturales renovables. En este caso, deberá ser el Director Ejecutivo del INDA, quien declare la expropiación, luego de fenecido el plazo que debe conceder para que se rectifiquen dichas prácticas, el que será de hasta dos años calendario y, en ningún caso, menor a un año; c) Cuando las tierras aptas para la explotación agraria se hayan mantenido inexplotadas por más de dos años consecutivos y siempre que no estuvieren en áreas protegidas, de reserva ecológica, constituyan bosques protectores o sufran inundaciones u otros casos fortuitos que hicieren imposible su cultivo o aprovechamiento; y, d) Cuando el predio esté sujeto a gran presión demográfica, siempre y cuando se incumpla por parte de sus propietarios los enunciados establecidos en los artículos 19,20 y 21 de esta Ley. La expropiación por esta causal sólo podrá hacerse cuando existan informes previos favorables y concordantes del Ministerio de Agricultura y Ganadería y de la Oficina de Planificación de la Presidencia de la República (ODEPLAN). Existe gran presión demográfica cuando la población del área rural colindante al predio, dependiendo de la agricultura para su manutención, no puede lograr la satisfacción de sus necesidades básicas, sino mediante el acceso al mismo. Para la aplicación de esta causal el INDA, a petición de la organización interesada y previa la zonificación de las áreas en que esta causal es aplicable, le solicitará al MAG y a la ODEPLAN el estudio correspondiente para determinar si se cumplen las condiciones establecidas en el literal d) de este artículo. No podrán ejercer el derecho de petición para la aplicación de esta causal las personas naturales y jurídicas que no estén dedicadas a la agricultura" (Ley de Desarrollo Agrario 2004, art. 43). 
tierras entregadas entre 1964 y $19928-$, sino con la titularización; dado que en el 2000 habían 992.000 ha sin título de propiedad (Laforge, 2008, p. 211) y aún en 2012 el 12\% de las UPA no tenían título de propiedad y el $60 \%$ no tenían registros actualizados (Landívar \& Yulán, 2016, p. 14). Entre 2000 y 2011 se legalizan 171.682 predios, en una actividad creciente que solo en 2010 comprendió la legalización de 25.257 predios que comprenden más de 418.600 ha (Rosero et al., 2011, p. 80; Tamariz, 2012, p. 23). Entre 2012-2015 el Plan de Legalización de Tierras legalizó "cerca de 236.000 títulos de propiedad" (MAGAP, 2016, p. 41).

La Ley de Tierras y Territorios Ancestrales (2016) y su Reglamento General de Aplicación (2017) no modificaron un ápice el panorama descrito9. Más allá, la iniciativa del último periodo que consistió como dice el MAGAP (2016) en empujar la "institucionalización [del] MAGAP y sus entidades adscritas: Instituto Nacional de Investigaciones Agropecuarias (INIAP), Agencia Ecuatoriana de Aseguramiento de la Calidad del Agro (AGROCALIDAD [en lugar del SESA]), Empresa Pública Unidad Nacional de Almacenamiento (UNA-EP), Instituto de Provisión de Alimentos (IPA)".

Sin embargo, el gasto de capital y de inversión fue, generalmente, mayoritario en la Comisión de Estudios para el Desarrollo de la Cuenca del Río Guayas (CEDEGE), Corporación Reguladora del Manejo Hídrico de Manabí (CRM) y el Programa Regional de Desarrollo del Sur del Ecuador (PREDESUR) y escaso en el MAGAP, siendo mayor la inversión entre 1999 y 2009 (Rosero et al., 2011, p. 41-76). "Se ha demostrado que el 65\% de los recursos destinados al sector agropecuario entre 1995 y 2009 se asignaron y fueron manejados por las corporaciones regionales [...] Recursos que esencialmente han cubierto el gasto corriente [...] el 77\% de los recursos para inversión fueron manejados por estas mismas corporaciones" (Rosero et al., 2011, p. 62 ), de donde se sigue que la iniciativa neoliberal de descentralización e iniciativas locales se extendió durante la modalidad posneoliberal de intervención estatal en el agro.

Si el fortalecimiento del Estado no fue un aspecto central en esta modalidad de la política agropecuaria ¿cuál fue el rol cumplido por el Estado?

\subsection{Encadenamientos productivos y agricultura por contrato}

La titularización permitió que la formalización de las relaciones de poder entre el campesinado y la clase capitalista del agro pudiera consolidarse. Dos políticas fueron centrales para cumplir este objetivo: el impulso a los encadenamientos productivos y, el más importante, la ampliación de la agricultura por contrato.

a) La política de Desarrollo Rural Integral, de la década de 1980, se abandonó y, en su lugar, se impulsaron los llamados "encadenamientos productivos", que se multiplicaron después del 2006 con los programas Proyecto de Competitividad Agropecuaria Rural Sostenible (CADERS), Programa Nacional de Negocios Rurales Inclusivos (PRONERI), Fondo para la Integración de Cadenas Agroproductivas (FICA) y se diferencian por su directa articulación al agronegocio. Primero se trató de distribuir úrea subsidiada. En el periodo 2007-2011 el Estado distribuyó 530.900 TM de úrea, el $70,34 \%$ se destinó a cultivos de cacao, arroz, café, maíz duro, banano y plátano (Aillon \& Milques, 2012, p. 41-42).

Es importante recordar que el predominio de la técnica moderna fue algo tardío en el caso de las semillas. El uso de semillas certificadas en la producción creció vertiginosamente en los últimos años. Así, en 2015, el 69\% del arroz y el 85\% del maíz se produjo con semilla certificada (MAGAP, 2016, p. 92), mientras que $60,4 \%, 31 \%$ y $95 \%$ de las semillas de brócoli, zanahoria y alfalfa, respectivamen-

8 En 2009 se lanzó el "Plan de Desarrollo Integral de las Haciendas del Estado" ("Plan Haciendas") para entregar los predios rústicos del Estado, posteriormente llamado "Plan de fomento del acceso de tierra a los productores familiares en el Ecuador" (conocido como "Plan Tierras") encargada a la Subsecretaría de Tierras y Reforma Agraria, creada en 2010 para reemplazar al INDA, que asegura haber entregado hasta 201530.000 hectáreas -el 3,3\% de la tierra entregada por la reforma agraria- (MAGAP, 2016 , p. 314). De este plan, entre 2010 y 2012, las tierras se entregaron en un " $80,9 \%$ en la Costa, $15,6 \%$ en la Sierra y $3,5 \%$ en la Amazonia" (Martínez, 2014, p. 148-149).

9 La diferencia, en el caso de esta normativa, es que las propuestas desde el sector campesino no tuvieron fuerza en el debate de la ley. 
te, fueron importadas de Estados Unidos entre 2000 y 2012 (Álvarez et al., 2014, p. 50-56). En 2010 el Estado entregó semillas de maíz certificadas y en 2013 se prolongó está política mediante un subsidio para el "kit o combo agrícola" comercializado por las empresas Agripac, Ecuaquímica, Pronaca/India, Interoc. A., Afecor y Del Monte (Yumbla \& Herrera, 2013, p. 16).

Como consecuencia de esta actividad, crecieron las grandes comercializadoras Fertisa, Delcorp, Ferpacific, Brenntag, que importan el $90 \%$ de las semillas comercializadas en el país ${ }^{10}$ (Vinueza 2009, p. 70), así como el resto de componentes del paquete tecnológico para el agro, en íntima vinculación con las corporaciones transnacionales del primer mundo.

Posteriormente, la creación en 2011 del FICA, un proyecto piloto con un presupuesto de 4 millones de dólares, permitió que empresas como Ecuaquímica, Agripac, Pronaca e Interoc se vincularan con representantes de los productores de maíz y arroz ubicados en Guayas, Los Ríos, Manabí y Loja (Yumbla \& Herrera, 2013, p. 12-17), es decir, en las zonas centrales de esos cultivos se extendió ampliamente esta relación.

b) La "agricultura por contrato" para Yumbla \& Herrera (2013, p. 14) -que, a su vez, retoman la idea de proletarios propietarios de Lenin11- es una vía de proletarización del campesinado dedicado a productos intensivos en fuerza de trabajo y materia prima12. En la misma línea argumentativa, Vinueza $(2009$, p. 7) la define como,

Los acuerdos formales escritos ${ }^{13}$ que se establecen entre pequeños productores organizados y la agroindustria, con el respaldo de un tercero, en los cuales la agroindustria ejerce algún control en los mecanismos de producción (transferencia tecnológica, capacitación en manejo productivo, crédito) y los productores por su parte, entregan la cosecha del producto, sus tierras y su trabajo, según lo establecido en el contrato.

Para promover esta modalidad el Estado impulsó el PRONERI en 2010 para vincular a los campesinos con la agroindustria. El programa contabilizaba, en 2013, casi 8.000 productores bajo agricultura por contrato en múltiples productos ${ }^{14}$. La agricultura por contrato creó un importante vínculo entre los pequeños campesinos y las empresas en los cultivos tradicionales de exportación: $37 \%$ en cacao, $36 \%$ en café y $14 \%$ en banano, y una gran variedad de productos: panela, cárnicos (incluye desde cuyes hasta camarón), frutales, quinua, malanga y achiote, etc. ${ }^{15}$

El mecanismo permite el control de enormes recursos productivos. Así, con casi 700 agricultores encadenados en 2007 en el cultivo de maíz y más de

10 "Según Agromar (2012), estas casas comerciales nacionales ofertan solo semillas de casas comerciales extranjeras, así, Agripac vende semillas de Syngenta (Trueno, NB-7253, NB-7254), Ecuaquímica de Monsanto (DK-7088, DK-5005, AG-003), Pronaca de Pioneer (30F35, P-3523, S-810) e Interoc de la empresa Advantage (Agri-104, Asvanta-105, Advanta-224). Ninguna de estas empresas vende semillas del Instituto Nacional de Investigaciones Agropecuarias (INIAP)" (Yumbla \& Herrera, 2013, p. 17).

11 Lenin (1974, p. 176) sostenía que el campesinado vinculado a la producción capitalista al suministrar productos terminados artesanales o materias primas agrícolas, aun cuando posee una mínima parcela que coadyuva al sostenimiento de la economía familiar, "ha ocupado un lugar del todo en el sistema general de la producción capitalista". Sin embargo, observó que la predominancia de la "tendencia a la diferenciación campesina", por un lado, o del progreso de la economía campesina, por otro, solo puede realizarse a partir de un examen más minucioso (Lenin, 1974, p. 179) para el cual no tenemos espacio en este ensayo.

12 Entre el 35-40\% del costo de producción de maíz, v. g., está relacionado con el paquete tecnológico y entre 27-52\% con la mano de obra (Vinueza, 2009, p. 70-74).

13 Se menciona 5 modelos contractuales: centralizado (contrato estacional entre la burguesía agraria y los campesinos), de plantación núcleo (contrato formal), de participación múltiple (contrato formal), extraoficial (informal) y de intermediarios (contrato campesino-intermediario y de este con la burguesía), así como sus combinaciones (Borja \& Castillo, 2013, p. 39).

14 "Las 10 empresas anclas son: Nestlé, Energy Palma, Floralp, Nintanga, Agroparaíso, Transmar, Triari, Canolandia, Cuycuna, El Ordeño, Ecuavegetal, Agroficial, Palmeras del Ecuador, Providencia” (Martínez, 2014, p. 150).

15 Se anota la presencia de este sistema para la producción de papa con Fritolay (Licto, Mulalillo), alcachofa con Inaexpo-Pronaca, leche con la empresa Nutri Leche y Unorlact (Cuenca, Biblián, en Cayambe 70\% de la producción pecuaria se dirige a la agroindustria), maíz con Inda-Pronaca (Ventanas y Balzar), brócoli con Provefrut (Gatazo Zambrano, San Pedro de Llucud). 
21.500 ha en 2012, Pronaca obtenía cerca del 20\% de la materia prima nacional por medio de contratos directos y $80 \%$ por la vía de intermediarios. En total, si se incluyen arroz y alcachofa, sumaban 30.500 ha en 2010 (Vinueza, 2009, p. 38).

La titularización de tierras, vista desde esta lógica, se convirtió en la punta de lanza para masificar la agricultura por contrato, dado que transforma en una contraparte adecuada a quien pueda garantizar la producción con su tierra ${ }^{16}$. La combinación de micro créditos, asistencia técnica y explotación del trabajo familiar configuró un triángulo en el que Martínez (2003, p. 59) incluye a las organizaciones empresariales, no gubernamentales y a los campesinos, aunque debiera señalarse al Estado como auspiciante de los dos primeros. Esta acción trae a la palestra, nuevamente, el triángulo sin base del periodo de la hacienda que anula, una vez más, la capacidad de decisión del campesinado sobre la producción que pierde autonomía productiva y tecnológica. Observamos aquí la subsunción real del campesinado al capital.

Esta modalidad ya fue practicada desde 1976 por la Standard Fruit y otras bananeras multinacionales (con contratos estables, asistencia técnica y crédito en Guayas y El Oro con más de 17.500 ha) en reemplazo de sus propias plantaciones (Larrea, 1985, p. 52). También, se presentó con antelación en los cultivos de maíz, sorgo, cebada (entre 1950-1960) y en la producción de leche (Urriola \& Cuvi, 1986, p. 165). La novedad radica en su extensión actual que es notoriamente mayor en la cantidad de tierra controlada y en la influencia sobre los productores que como afirma Lewontin, mencionado por Vinueza (2009, p. 17), conduce a su pérdida de control sobre el proceso de producción y comercialización.

\subsection{Políticas de impulso a las exportaciones y la agroindustria}

En esta sección se estudian tres elementos: el presupuesto estatal para la agricultura, la normativa agraria y la política de precios.

\section{a) El presupuesto estatal para la agricultura}

El presupuesto estatal para la agricultura -que se redujo en relación al Presupuesto General del Es- tado, pero se expandió nominalmente de 100 a 350 millones de dólares entre 2006 y 2014- (MAGAP, 2016, p. 216) se destinó para obras de infraestructura de riego y servicio técnico agrícola en territorios que no son grandes productores para la alimentación interna ni tienen mayores dificultades estructurales o de ingresos, es decir, en las zonas de predominancia de la agroindustria (Carrión \& Herrera 2012, p. 63-68). Lo que sucedió es que, como afirma Paredes (2013, p. 149), paladín del liberalismo, "el Estado debe crear un buen entorno [...], pero las respuestas están en manos privadas".

La actuación del Estado en este periodo pareciera estar a tono con la prescripción de Paredes (2013). Aunque es evidente una fuerte contracción de la importancia relativa de este gasto, no se puede afirmar por esto que el Estado dejó de ser importante para los cambios en el sector agrario. De hecho, el apoyo estatal fue fundamental. "La contradicción de la que habla Lechner (1997) fue evidente: pese a los discursos anti estatales, los grupos de poder económico requieren de su control para imponer los cambios en la economía" (Barrera, 2001, p. 111). Se trató siempre de una disputa de poder, batalla en la que el "juez" jugó siempre a favor de un equipo, el más poderoso. De ahí el papel decisivo con el que aparece la política en la actividad económica y, en el fondo, su rol en la consolidación de las clases que impulsan estas modificaciones.

\section{b) La normativa agraria}

Centenares de leyes, reglamentos, instructivos, resoluciones, decreto ejecutivos, acuerdos ministeriales, acuerdos de comercio exterior, bolsas de productos, precios de sustentación, prohibiciones y permisos de importación, ruedas de negocios, acuerdos internacionales, certificados, aranceles, acuerdos bilaterales y multilaterales, consejos consultivos, de comercio exterior, de negociación, sub consejos, mesas técnicas, proyectos, planes, programas, estrategias, agendas y políticas públicas, que mantuvieron la trama del poder tras bastidores y potenció de forma sostenida la agroindustria y la agricultura de exportación. La forma de emitir la normativa agraria varió. Los grandes debates sobre la Ley agraria no son centrales porque la normativa agraria fundamental ya no se define en el legislativo. Es, por decir-

16 El modelo hace que las pérdidas las asuman los campesinos y la empresa "externaliza costos, ya que no debe responder ni se hace cargo de pagos al IESS, utilidades, seguridad e higiene en el trabajo, etc.” (Harari, 2013, p. 47). 
lo así, en la letra pequeña donde se regula el agro. Pero, no es solo un cambio de recinto. El meollo del asunto es la traslación de la soberanía desde la representación de la llamada "voluntad general" hacia un conjunto de actores ad hoc -lobistas y, con frecuencia directamente, empresarios agroindustriales y agroexportadores- que no pasaron por un proceso de sufragio y tienen la potestad de definir los destinos del sector agropecuario. Además, para el sector campesino es casi imposible dar seguimiento a tan menuda regulación ${ }^{17}$.

\section{c) La política de precios}

La política de precios agrícolas se caracterizó, históricamente, por tener una marcada periodicidad. Tras finalizar las políticas de control de precios ${ }^{18}$ de las décadas de 1970 y parte de la década de 1980 , se inició la liberalización de precios ${ }^{19}$ que desarrolló lo que el MAGAP (2016, p. 35) llama "especialización con énfasis en la producción agropecuaria exportable $[. .$.$] de productos tradicionales y no tradi-$ cionales". En esta coyuntura fueron desfavorecidos los productores pequeños, sobre todo, dedicados al mercado interno cuyos productos se encarecieron en relación a los importados (Vos, 1988, p. 461) que, por su parte, vieron reducidos sus beneficios, posteriormente, con el crecimiento de los costos a raíz de la dolarización.

La modalidad posneoliberal hegemonizó la política agraria en un momento signado por el crecimiento de los precios de los commodities, duplicados entre 2000-2014 (MAGAP, 2016, p. 37), mejorando los términos de intercambio en el banano, carne, palma africana, azúcar, cacao, mango y otros, siendo claro que "el incremento de precios fue mayor en los productos de exportación y agroindustriales que en los campesinos; paradójicamente los precios de los productos campesinos son más inestables que los precios de los productos de exportación" (Carrión \& Herrera, 2012, p. 106). Este factor, aunado a los límites para los pequeños campesinos señalados en los acápites anteriores, coadyuvó a fortalecer la sub-

17 Por ejemplo, el Reglamento a la Ley para Estimular y Comercializar el Banano, Plátano y Otras Musáceas (2011) y su instructivo (2012), el Reglamento de comercialización de maíz (2013), el Comprobante de Origen Nacional de Productos Agropecuarios (2013) y su instructivo (2014), las Resoluciones 585 (2010) y 102 (2013) del COMEX, los Decretos Ejecutivos N 1303 (2012), №136 (2013), el Consejo Consultivo de la Palma Aceitera Grasas y Aceites (2003), la Mesa técnica del trigo y panadería (2010), la actualización del Consejo Consultivo del Arroz (2010), el Consejo Consultivo de Cebolla y la Unidad de Registro de Transacciones y Facturación (2010), el Consejo Consultivo de Algodón (2011), la Mesa de negociación del plátano (2011), el Sub consejo de la cadena porcicultora, industrias y comercio (2012), el Plan de Desarrollo Agropecuario y Agroindustrial 2000-2003 (2000), la Política Agropecuaria Común Andina (2001), los Programas de crédito blando con la Corporación Financiera Nacional (2011), la Estrategia Agropecuaria Ecuatoriana 2005-2015 (2005), la Agenda para la Transformación Productiva 2010-2013, el programa de semillas de alto rendimiento para maíz y arroz (2014), la vinculación de la agroindustria con programas del gobierno como "Aliméntate Ecuador" y “Alimentación Escolar", la fijación del precio de sustentación del banano (2004-2005), el manejo discrecional de la prohibición o permiso para las importaciones de arroz, azúcar, maíz, las ruedas de negocios (2013), el Acuerdo de Complementación Económica con Chile (1993 actualizado en 2008), el Acuerdo de Cooperación Comercial con Turquía (2016), el Acuerdo de Alcance Parcial con Guatemala (2013), el Acuerdo Comercial con Irán (2013), el Sistema de Preferencias Generalizadas (SGP) reemplazado luego por el Acuerdo Multipartes con la Unión Europea (2017), entre otros muchos casos

18 Entre 1973 y 1985 se extendieron políticas de control de precios, una tasa de cambio sobrevaluada (entre 1972 y 1977), altos aranceles y licencias de importación llevó a la protección frente a las importaciones de: azúcar (prohibida en 1970), leche en polvo, café (entre 1980 y 1989) y maíz, y un sistema de subsidios para remediar pérdidas en el agro, impulsar el cambio tecnológico y reducir la inflación (en especial para maíz, arroz, trigo, azúcar y leche) (Ramón, 1991, p. 183; SIPAE, 2007, p. 22). En este momento, "los términos de intercambio para los alimentos dirigidos al mercado interno fueron negativos entre 1968 y 1981 " (Vos, 1988, p. 457). Las políticas de precios intentaron controlar la inflación presente entre 1965 y 1982 en los alimentos, sobre todo de productos pecuarios (Vos, 1988, p. 459) aunque crecen más los precios no agrícolas.

19 Los agroexportadores "perjudicados" por la política de control de precios, posteriormente, impusieron sus intereses al eliminarlo "entre mediados de la década de 1970 e inicios de 1990 ([pasaron] de 40 a 4) y en 1992 son anulados [totalmente]" (Chiriboga \& Arellano, 2013, p. 12). Esto se dio en un contexto de recuperación de los precios de los productos de exportación: cacao (19651982), banano (entre 1973 y 1982), café (entre 1972 y 1979), palma africana (desde 1978), devaluando la moneda para mejorar la competitividad externa (minidevaluaciones desde 1983). Se eliminaron los impuestos a las exportaciones con la Ley 74 de Facilitación de Exportaciones (1993), se redujeron los aranceles en 1990 (de entre 0\%- 300\% a entre 5\%-20\%) y las barreras de importación que incluyen productos de exportación de producción campesina (café, cacao y algodón), y se dividió la producción agrícola en productos sensibles (como arroz, papa y maíz) y poco sensibles (Chiriboga \& Arellano, 2013, p. 13). 
sunción formal del campesinado al capital ${ }^{20}$, en los sectores donde, previamente, los vínculos entre estos y la agroindustria eran débiles.

\subsection{La situación de la agroindustria y la agricultura de exportación}

Según el Centro de Estudios de Estado y Sociedad -CEDES- (en Arboleda, 1988, p. 14), "agroindustria es la actividad que, partiendo del primer procesamiento de todo producto de origen vegetal o animal, lo transforma en otro producto apto para el consumo directo o en un insumo". La agroindustria no inicia con la reforma agraria, pues con anterioridad tenían presencia los ingenios azucareros, las plantaciones bananeras e incluso las piladoras de arroz (considerada industria rural), pero a lo largo del periodo estudiado adquiere predominancia en el sector agrícola, mientras la producción campesina se hace marginal en relación a la producción nacional.

Hasta la década de 1980 existían múltiples dificultades, entre otras, por la escasez de materia prima, el escaso desarrollo de industrias complementarias como envases, enfriamiento, del transporte y la importante competencia de productos sustitutos de origen campesino, leche y fruta fresca, manteca, panela, etc. En el siguiente período estas dificultades fueron subsanadas en una combinación de inversión estatal y privada. La necesidad de la agroindustria de una producción continua impuso, por un lado, estándares de calidad a los insumos y escalas de precios en función de estos indicadore ${ }^{21} \mathrm{o}$, también, la par- ticipación directa de las empresas agrondustriales en el cultivo (Urriola \& Cuvi, 1986, p. 165). Esto, por otro lado, provocó una fuerte demanda de materias primas: oleaginosas, fibras, leche, cereales, ganado, etc., con un alto componente de demanda intermedia: 47\% entre 2007 y 2013 (MAGAP, 2016, p. 105), que no siempre es satisfecho por la producción nacional primaria.

El peso de la agroindustria en el Producto Interno Bruto (PIB) es enorme. Bajo la "noción ampliada de agricultura", que agrupa a la agricultura y la industria vinculada, representó el 14\% del PIB en 2013, superando incluso a ramas como petróleo y minas $(13 \%)$ o a la manufactura (12\%). Es más, si se agrega a esta noción ampliada la producción no comercial -que incluye autoconsumo, semillas, alimento para animales y otros- la agricultura ampliada llegó al 19\% del PIB (MAGAP, 2016, p. 99-103)22. La contribución al Valor Agregado Bruto (VAB) del sector manufacturero de las ramas de alimentos, bebidas y tabaco; textiles, prendas de vestir e industrias de cuero; madera y muebles; y papel, imprenta y editoriales, en promedio entre 1993 y 2007 , fue del 7,3\% del PIB y en 2007 del 55,9\% del VAB de la industria manufacturera ${ }^{23}$. Dentro de la industria de alimentos y bebidas el VAB de los sectores de carnes, camarón y pescado aportan con el 64\%, mientras que juntos grasas, lácteos, molinería, azúcar y bebidas abarcan el 28,6\% (Carrillo, 2009, p. 2).

En contraste con la importancia que tiene el sector, su impacto en el empleo es menor que en el

20 Marx (1971, p. 55-72) señala: “que el trabajo se haga más intenso o que se prolongue la duración de la jornada laboral; que el trabajo se vuelva más continuo y bajo la mirada interesada del capitalista, más ordenado, etc., no altera en sí y para sí el carácter del proceso de trabajo" y esto "corresponde a la subsunción formal del trabajo al capital", en tanto el proceso de producción no consigue la autonomía necesaria respecto a la fuerza de trabajo, por cuanto es esta la que sigue determinando el ritmo de trabajo. Tal independencia solo se alcanza mediante el uso capitalista de la técnica con la organización industrial del proceso de producción, que marca el surgimiento de un "modo de producción específicamente capitalista".

21 Se evalúan los porcentajes de humedad, el nivel de impurezas, la acidez, presencia de hongos, etc. (Urriola \& Cuvi, 1986, p. 29-36).

22 La importancia del sector agrícola es mayor. Ramón (1991, p. 161) advertía que por fotografía aérea se evidenciaba un subregistro de la superficie agraria en el censo y el MAGAP (2016) recientemente confirmó esto mediante imagen satelital. "Consecuentemente, las cuentas nacionales agrícolas arrastran este subregistro pues utilizan la ESPAC como fuente primaria. [...] Ahora esta información no recoge la producción agropecuaria total del país dado que la ESPAC no consulta ni registra los cultivos principales de la Amazonía, ni de la Sierra, sino principalmente los de la Costa. De un total de 120 cultivos que se practican en el país, la ESPAC recoge información solo de 25. Además, no recoge apropiadamente la producción de la pequeña agricultura campesina (alrededor del 55\% de las UPA según este mismo estudio) por ser unidades muy pequeñas que continúan fragmentándose (aproximadamente el 58\% del total de UPA del país son predios de menos de cinco hectáreas), cuya localización es de difícil acceso y dispersa" (MAGAP, 2016, p. 101-107).

23 El peso de este sector pasó del 69,7\% al 53,6\% entre 1966 y 1986 reducción que se debe principalmente por la pérdida de importancia de la rama de alimentos desde 1972, al inicio de la explotación de petróleo. Aun así, en 1986 estos sectores representaban el 56,3\% del VAB manufacturero (Palan, 1989, p. 58-61) y en 1978 el 72\% del empleo industrial (Urriola, 1988, p. 478, 476). 
resto de la manufactura por "el carácter de la tecnología incorporada en los últimos años en la agroindustria ha tendido a ahorrar mano de obra" (Urriola, 1988, p. 476-478), por esta razón el 92\% del empleo de alimentos y bebidas se generaba en micro, pequeñas y medianas empresas (Cadena, 2013, p. 43). Sin embargo, "en la industria de alimentos y bebidas el 93,9\% de las empresas son grandes" (Carrillo, 2009, p. 4) y en la producción agrícola más amplia Chiriboga \& Arellano (2013, p. 31) se constató una creciente concentración del poder económico a medida que avanza la cadena productiva (ver Tabla 2).

Tabla 2. Poder de las empresas agroindustriales más grandes

\begin{tabular}{|c|c|c|}
\hline & Década de 1980 & 2010 \\
\hline Balanceados & $\begin{array}{l}\text { 1955: } 1 \text { empresa; 1977: } 25 \text { empresas. En 1984: } 41 \text { em- } \\
\text { presas, 47\% de balanceados } 3 \text { empresas }\end{array}$ & \\
\hline Molinería & $\begin{array}{l}\text { 1981: } 6 \text { empresas procesaban el } 79 \% \text { del trigo y el } 55 \% \\
\text { de la venta de harina de trigo lo controlan } 2 \text { empresas, } \\
337 \text { unidades el } 2,6 \% \text { de la producción de harina. Tres } \\
\text { empresas controlaban todas las importaciones }\end{array}$ & Pastas: $54 \%$ en 2 empresas \\
\hline Aceites y grasas & $\begin{array}{l}\text { 1985: } 12 \text { empresas, } 4 \text { controlaban el } 70,9 \% \text { de la produc- } \\
\text { ción }\end{array}$ & $\begin{array}{c}1 \text { empresa el } 58 \% \text { de las ventas y las } 13 \\
\text { empresas restantes lo demás }\end{array}$ \\
\hline Cervezas & $\begin{array}{l}\text { 1940: se eliminaron } 20 \text { empresas y solo quedan } 3 \text { con } \\
\text { alta participación o control total de capitales extranjeros }\end{array}$ & \\
\hline Lácteos* & $\begin{array}{c}\text { 1977: } 6 \text { empresas procesaban el 66\% de la leche, } 49 \text { el } \\
\text { 23\% y } 225 \text { más artesanales el 10\%. En 1984: } 5 \text { empresas } \\
\text { el } 75 \% \text { de la producción }\end{array}$ & $\begin{array}{l}5 \text { empresas controlan el } 61 \% \text { de las } \\
\text { ventas }\end{array}$ \\
\hline Conservas** & 1983: 2 empresas el 60\% del mercado de jugos & $\begin{array}{l}\text { 81\% de las ventas en } 1 \text { empresa (bebidas } \\
\text { no alcohólicas) }\end{array}$ \\
\hline
\end{tabular}

* En 2013 el 72,4\% de la leche es vendida en líquido y 25,2\% se consume o procesa en las UPA (Urdiales, 2015, p. 12-13). Entre 1973 y 1980 de la leche destinada al consumo humano la leche pasteurizada decreció del 50\% al 28\%, creciendo el consumo de leche cruda del $46 \%$ al $66 \%$ en tanto que la producción de derivados ocupaba entre $8 \%$ y $10 \%$ (CENDES/ FES-ILDIS, 1982, p. 218). En 2007 de la leche destinada al mercado cerca del $40 \%$ se utilizaba en derivados y el 75\% pasaba por pasteurización (Cárdenas, 2009, p. 114).

** El 60\% de la producción era concentrado de tomate y el resto en gran cantidad productos.

Fuente: Urriola \& Cuvi (1986, p. 21-147); Cadena (2013, p. 44).

Las 100 grandes empresas agro industriales subieron su control sobre el mercado, medido por sus ingresos anuales en relación al total de ingresos de las empresas agroindustriales, que pasaron del $54 \%$ al 65\% entre 2006 y 2013 (CDES, 2016). Los grandes beneficios que obtienen estas empresas se deben al sólido proceso de explotación de la fuerza de trabajo que, en parte, aparece al obervar la gran desigualdad en la distribución de la riqueza entre capitalistas y trabajadores,
30 veces en el sector primario, frente a 17 veces en la manufactura, o 16 veces en el sector servicio, para el año 2010. Con el agravante que esta relación tiene una tendencia negativa para el trabajador primario (agricola), entre 2007-2010. (MAGAP, 2016, p. 311).

La tendencia se atenúa en los lugares donde predomina el trabajo agrícola por cuenta propia, por eso Carrión \& Herrera (2012, p. 125) concluyen que 
"las zonas agroindustriales registran los mayores índices de explotación laboral".

Por su parte, los productos de exportación representan más del 50\% del PIB agropecuario, destacándose en algunos años ciertos productos (como el camarón en 1998 o las flores en 2007), pero siendo permanente la importancia del banano y cacao que son de bajo valor agregado (Guerrero \& Sarauz, 2015 , p. 2). Entre 1948-1972 el banano fue el 50\% de las exportaciones del país, luego la tendencia cambia por la explotación petrolera (Larrea, 1985, p. 47). Pero las exportaciones agropecuarias se recuperaron entre 2000 y 2013, llegando a ser en promedio el $78,6 \%$ de las exportaciones no petroleras (siendo el 91\% de las exportaciones agropecuarias banano, camarones y pescado, flores y cacao) (MAGAP, 2016).

Los cambios significaron el decrecimiento de la producción de alimentos por la producción agroindustrial y de exportación, empujando al incremento de la importación de alimentos, que, aunque todavía es baja, creció en un 750\% entre 1990 y 2009 (Rosero et al., 2011, p. 61). En 1979 se podía contar entre los 10 cultivos de mayor área sembrada a solo dos cultivos agroindustriales o de exportación y entre los 25 primeros solo ocho. Entre 2000 y 2010 la relación se invirtió, de los 10 primeros cultivos por su área sembrada solo 3 no son agroindustriales o de exportación y entre los 20 primeros no lo son 8 (Lajo, 1988, p. 56; Viejo, 2013, p. 21). De hecho, desde la década de 1950 las pasturas crecieron significativamente hasta llegar, en 2013, al 63\% de la superficie agrícola, especialmente en la Sierra (Urdiales, 2015, p. 39).

En la actualidad, no se puede estudiar la actividad agrícola por fuera del sistema industrial, tanto si está destinado para el mercado interno o al externo. Es más, podemos afirmar que la agroindustria y la agricultura de exportación se consolidaron como el elemento predominante y organizador del agro ecuatoriano y, considerando la relevancia de este sector dentro de la economía nacional, aseveramos que la agroindustria y la agricultura de exportación son el nodo central de los intereses económicos de la clase dominante ecuatoriana, su fuente de acumulación primaria. De hecho no se puede explicar el carácter y la articulación de la política agraria sin reconocer el poder y peso del sector agroindustrial en Ecuador o, para decirlo en otros términos, la clase dominante del país tiene sus raíces en el agro y desde allí acumula el capital necesario para poner bajo su control a otros sectores de la economía ${ }^{24}$; ergo, el Estado responde a sus intereses por estar conducido personalmenete por estos sectores o porque no puede ignorar sus demandas dado su enorme poder económico.

\section{Apuntes finales}

La modalidad posneoliberal de intervención del Estado en el agro ecuatoriano, mediante la política agraria, apuntaló las transformaciones de las relaciones de poder dentro de esta rama de la economía, pero no para volverlas más justas, sino para reforzar el poder/ sobre, esto es, la dominación del capital personificado: de los capitalistas-terratenientes. Esta clase social, determinante en las directrices del Estado sobre el agro, debe su poder a la mopolización de los medios de producción que incluyen: las tierras de mejor calidad y ubicación en relación a los mercados, el usufructo de la técnica -mecanización, riego, agroquímicos- para conseguir ventajas comerciales, el acceso al crédito para conseguir estas mejoras, la subsunción de otras clases actuantes en el campo -tanto de la clase trabajadora agrícola, en calidad de fuerza de trabajo, como del campesinado para el suministro de materias primas-, entre otros factores.

Es pertinente advertir que la política agraria permite avizorar la transformación del Estado ecuatoriano desde su forma oligárquica hacia una forma de Estado moderno, no por esto exento de contradicciones. De allí que se observe, como una constante y casi como una marca de nacimiento, la permanencia de aquel triángulo sin base del periodo de la hacienda resignificado y reinventado a lo largo de medio siglo con diferentes actores y en diferentes contextos en aras de la acumulación de riqueza en un polo de la sociedad. Se trató de una disputa de poder en la que el "juez" jugó siempre a favor de un equipo, el más poderoso. De ahí el papel decisivo con el que aparece la política en la actividad económica y, en el fondo, su rol en la consolidación de las clases que impulsan estas modificaciones. En definitiva, no se puede pensar a Ecuador sin el problema agrario y la política agraria es un mirador privilegiado de éste.

El Estado en este caso no es un actor imparcial, pero tampoco podemos aducir que es un instrumento. Es, en tanto relación social, un macro dispositi- 
vo para la reproducción de la relación de capital en escala ampliada. Es decir, que el funcionamiento del Estado permite la perpetuación de la explotación de la fuerza de trabajo al coadyuvar a la expansión de las condiciones de posibilidad de esta relación, condiciones que no son otra cosa que el monopolio de una de las fuentes del poder social, para nuestro caso los medios de producción del agro, con una diferencia: se produjo la legitimación de la intervención estatal en el agro en el periodo posneoliberal bajo el discurso de los encadenamientos productivos, el emprendimiento y la legalización de tierras.

\section{Referencias}

Aillon, M., \& Milques, L. (2012). Evaluación del programa de distribución de úrea que comercializa el Banco Nacional de Fomento a nivel nacional. Universidad Central del Ecuador.

Álvarez, T., Bravo, E., \& Armendaris, E. (2014). Soberanía alimentaria y acceso a semillas hortícolas en el Ecuador. La Granja, 20(2), 45-57. https://doi.org/10.17163.lgr.n20.2014.05

Arboleda, M. (1988). La agroindustria en el Ecuador. Foro, Quito: ILDIS.

Artous, A. (2016). Marx, el Estado y la política. Barcelona: Editorial Sylone.

Barrera, A. (2001). Acción colectiva y crisis politica. El movimiento indígena ecuatoriano en la década de los noventa. Quito: Centro de Investigaciones CIUDAD/ Ediciones Abya-Yala/ OSAL/ CLACSO.

Barsky, O. (1988). La reforma agraria ecuatoriana. Quito: Corporación Editora Nacional.

Brassel, F., Ruiz, P., \& Zapatta, A. (2008). La Estructura agraria en el Ecuador: una aproximación a su problemática y tendencias. En ¿Reforma agraria en el Ecuador?: viejos temas, nuevos argumentos (pp. 17-30). Quito: SIPAE.

Borja, J., \& Castillo, J. (2013). "La "agricultura bajo contrato": contribución al debate teórico; Ecuador: casos de maíz en Guayas, brócoli en Chimborazo y leche en Carchi". En Agricultura bajo contrato en el Ecuador: elementos para el de-
De poco sirven las fórmulas y los slogans de las décadas de 1960 y 1970 cuando la realidad se trastocó. En consecuencia, la crítica al statu quo del agro ecuatoriano -constantemente caracterizado por la concentración de la riqueza y la desigualdad de oportunidades y capacidades- y el posicionamiento con los sectores más desfavorecidos por esta realidad no puede pasar por alto el problema del poder -de la capacidad de alterar las posibilidades futurasque se deriva de la monopolización de estos medios de producción.

bate (pp. 31-62). Quito: SIPAE / Agrónomos y veterinarios sin fronteras.

Cadena, S. (2013). Análisis de la competitividad y la concentración de mercado en la industria de alimentos y bebidas en el Ecuador durante 2000-2008. Facultad Latinoamericana de Ciencias Sociales Sede Ecuador..

Cárdenas, C. (2009). Ecuador, ¿país agropecuario? Análisis de la situación de los agronegocios en el Ecuador. Buenos Aires: Universidad de Belgrano.

Carrillo, D. (2009). La industria de alimentos y bebidas en el Ecuador. Quito: Instituto Nacional de Estadística y Censos.

Carrillo, G. (2013). Transformaciones agrarias y organización social. Universitas, Revista de Ciencias Sociales y Humanas de la Universidad Politécnica Salesiana del Ecuador, XI(19), 181-216.

Carrillo, G. (2016). Pasado y presente de la reforma agraria en Ecuador (1948-1973). Ponencia para la Conferencia Internacional: Old and New Worlds: The Global Challenges of Rural History. Lisboa: ISCTE-IUL, 27-30 enero 2016.

Carrión, D., \& Herrera, S. (2012). Ecuador rural del siglo XXI. Quito: Instituto de Estudios Ecuatorianos.

CDES. (2016). Desconcentremos el campo por el derecho a la alimentación. Infografías agroindustria. Obtenido de: http://cdes.org.ec/ 
web/desconcentremos-el-campo-por-el-derecho-a-la-alimentacion/

CENDES/ FES-ILDIS. (1982). Diagnóstico de la agroindustria ecuatoriana, Tomo II. Quito: CENDES/ FES-ILDIS.

Chauveau, Ch. (2008). Reflexión sobre la función socio económica de la tierra y el modelo de desarrollo agrario. En ¿Reforma agraria en el Ecuador?: viejos temas, nuevos argumentos (pp. 189-201). Quito: SIPAE.

Chiriboga, M. (1985). La crisis agraria en el Ecuador: tendencias y contradicciones del reciente proceso. En La economía política del Ecuador: Campo, Región, Nación (pp. 91-132). Quito: Corporación Editora Nacional.

Chiriboga, M., \& Arellano, F. (2013). Diagnóstico de la comercialización agropecuaria en Ecuador implicaciones para la pequeña economía campesina y propuesta para una agenda nacional de comercialización agropecuaria. Quito: CESA/ VECO Ecuador.

Cosse, G. (1984). Estado y agro en el Ecuador: 1960-1980. Quito: Corporación Editora Nacional.

COTECA, Compañía Técnica Agropecuaria. (2000). Mercado de tierras en Ecuado". En Antología de estudios rurales (pp. 95-119). Quito: FLACSO/ ILDIS.

Foucault, M. (1991). La gubernamentalidad. En Espacios de poder (pp. 9-26). Madrid: La Piqueta.

García, F. (2006). El sector agrario del Ecuador: incertidumbres (riesgos) ante la globalización. Íconos, 24, 71-88.

Gondard, P., \& Mazurek, H. (2001). 30 años de reforma agraria y colonización en el Ecuador (1964-1994): dinámicas espaciales. En Dinámicas territoriales. Políticas nacionales, presiones externas, mercado y movimientos sociales: los territorios cambian y su fisonomía revela los nuevos equilibrios. Ecuador, Bolivia, Perú, Venezuela (pp. 15-40). Quito: CGE/ CEN/ IRD/ PUCE.

Guerrero, M., \& Sarauz, S. (2015). Panorama agroeconómico del Ecuador, una visión del 2015. Quito: Ministerio de Agricultura, Ganadería, Acuacultura y Pesca.
Harari, R. (2013). Los productos agrícolas no tradicionales de exportación y las condiciones de trabajo: algunos ejemplos en Ecuador. Quito: IFA/ FOS.

Hidalgo, T. (2010). Reforma agraria. Ideología y política. Quito: Ediciones La Tierra.

Laforge, M. (2008). Cómo las agriculturas campesinas intentan asegurar su acceso a la tierra en el Ecuador: logros y obstáculos para un uso eficiente de la tierra. En ¿Reforma Agraria en el Ecuador?: viejos temas, nuevos argumentos (pp. 203-217). Quito: SIPAE.

Lajo, M. (1988). ¿La industria contra la agricultura? Desarticulación entre el agro y la industria alimentaria en los países andinos. Lima: CENES.

Landívar, N., \& Yulán, M. (2016). Ley de Tierras Rurales y Territorios Ancestrales: ¿Ampliando la protección de los derechos humanos? Un análisis desde la gobernanza responsable de la tenencia de la tierra. Quito: CEDOCUT.

Larrea, C. (1985). El sector agroexportador y su articulación con la economía ecuatoriana durante la etapa bananera (1948-1972): subdesarrollo y crecimiento desigual. En La economía política del Ecuador: Campo, Región, Nación (pp. 3590). Quito: Corporación Editora Nacional.

Lenin, V. (1974). El desarrollo del capitalismo en Rusia. El proceso de formación del mercado interior para la gran industria. Moscú: Editorial Progreso.

MAGAP, Ministerio de Agricultura, Ganadería, Acuacultura y Pesca. (2016). La política agropecuaria ecuatoriana: hacia el desarrollo territorial rural sostenible: 2015-2025. I Parte: El sector agropecuario ecuatoriano: análisis histórico y prospectiva a 2025. Quito: MAGAP

Madrid, T. (2018). Las taxonomías sobre los agentes económicos en el agro ecuatoriano 1965-2015. Contexto, supuestos teóricos, aportes y límites. Universidad Central del Ecuador.

Martínez, L. (1984). Pobreza rural y migración. En Ecuador agrario: ensayos de interpretación (pp. 72-93). Quito: Editorial El Conejo/ ILDIS. 
Martínez, L. (2003). Dinámicas rurales en el subtrópico. Quito: CAA

Martínez, L. (2014). De la hacienda al agronegocio: agricultura y capitalismo en Ecuador. En Tierra y Poder en América Latina (1982-2012) (II) (pp. 123-258). Buenos Aires: Ediciones Continente.

Marx, C. (1971). El capital, Libro I, Capitulo VI (inédito). Resultados del proceso inmediato de producción. México: Siglo XXI Editores.

Neto, J. (2011). Introdução ao estudo do método de Marx. São Paulo: Expressão Popular.

Ospina, P. (2011). El naufragio de una promesa. La redistribución agraria en la revolución ciudadana”. En Tierra urgente (pp. 43-48). Quito: Ediciones La Tierra/ SIPAE/ OXFAM.

Palan, Z. (1989). La nueva cara del agro ecuatoriano. Estado, crisis y agroindustria. Quito: Centro de Investigaciones CIUDAD.

Paredes, P. (2013). Revolución Ciudadana: Tanto... para tan poco. Quito: Universidad San Francisco de Quito.

Ramón, G. (1991). Indios, tierra y modernización: Cayambe-Ecuador. En Memoria del Seminario Internacional: Los campesinos en el proceso latinoamericano de los años ochenta y sus perspectivas, Tomo I (pp. 157-210). Cuenca: IDIS - Universidad de Cuenca.

República del Ecuador. Ley de Desarrollo Agrario. (2004). Quito, Ecuador.

Rodríguez, E. (2008). Competencia desigual: Agroindustria bananera y pequeños productores, el caso de Barbones. En ¿Reforma Agraria en el Ecuador?: viejos temas, nuevos argumentos (pp. 65-75). Quito: SIPAE.

Rosero, F., Carbonell, Y., \& Regalado, F. (2011). Soberanía alimentaria, modelos de desarrollo y tierras en Ecuador. Quito: CAFOLIS-Grupo Apoyo.

SENPLADES. (2009). Plan Nacional para el Buen Vivir 2009-2013: Construyendo un Estado Plurinacional e Intercultural. Quito: SENPLADES.
SIPAE. (2007). Hacia una agenda para las economías campesinas en el Ecuador. Quito: SIPAE.

Tamariz, R. (2012). El Instituto Nacional de Desarrollo Agrario (INDA) como gestor del desarrollo del sector rural. Universidad Católica de Cuenca.

Urdiales, J. (2015). Diagnóstico del sector lechero y propuesta para su desarrollo en las parroquias rurales del cantón Chordeleg. Cuenca: Universidad de Cuenca.

Urriola, R. (1988). Agroindustria y producción de alimentos. En El problema agrario en el Ecuador (pp. 463-482). Quito: ILDIS, Antología de las ciencias sociales.

Urriola, R., \& Cuvi, M. (1986). La agroindustria en el Ecuador en los años 80. Quito: CEPLAES/ ILDIS.

Viejo, K. (2013). Estudio de la cadena de valor de la caña de azúcar (SaccharumOfficinarum) en el recinto Tres Postes de la provincia del Guayas. Milagro: Universidad Agraria del Ecuador.

Vinueza, A. (2009). La inserción de pequeños productores maiceros organizados del cantón Ventanas en la agricultura por contrato y el desarrollo local. Quito: Facultad Latinoamericana de Ciencias Sociales Sede Ecuador.

Vos, R. (1988). Producción, empleo y tecnología. En El problema agrario en el Ecuador (pp. 439-462). Quito: ILDIS, Antología de las ciencias sociales.

Yumbla, M., \& Herrera, R. (2013). ¡No todo lo que brilla es oro! Agricultura bajo contrato: nueva forma de extracción del capital en el Socialismo del Siglo XXI. En Agricultura bajo contrato en el Ecuador: elementos para el debate (pp. 11-30). Publicaciones Nacionales de Proyecto Mercados Campesinos. Quito: SIPAE / Agrónomos y veterinarios sin fronteras. 